\title{
World Journal of Monteggia equivalent lesion in children: a narrative review
}

Lujie Xu (10), Wensong Ye, Haibing Li, Jingfang Xu, Weiwei Zhu, Zhefeng Zhen, Yi Yang

To cite: $\mathrm{Xu}$ L, Ye W, Li H, et al. Monteggia equivalent lesion in children: a narrative review. World Jnl Ped Surgery 2021;4:e000283. doi:10.1136/wjps-2021-000283

Received 17 March 2021 Accepted 23 June 2021
Check for updates

(C) Author(s) (or their employer(s)) 2021. Re-use permitted under CC BY-NC. No commercial re-use. See rights and permissions. Published by BMJ.

Department of Orthopaedics, Zhejiang University School of Medicine Children's Hospital, Hangzhou, Zhejiang, China

Correspondence to

Dr LujieXu; xulujie@zju.edu.cn

\section{ABSTRACT}

Background Monteggia equivalent lesion represents a group of injury or combined injury patterns that resemble the Monteggia lesion in its presentations and mechanisms. Unlike Monteggia lesions, the equivalent ones, which share vague definitions and mostly occur as sporadic single case reports in the literature, have not been thoroughly reviewed since Bado first proposed the term, especially in the pediatric population. The objective of this review was to elucidate the definition by elaborating on its clinical styles and thus analyzing the mechanism, diagnosis, and management through related literature.

Data sources Based on the terms of 'Monteggia equivalent', 'radial neck fracture' and 'pediatric', all of the related literature was searched on the PubMed and Google Scholar search engine.

Results The advance of the definitions for pediatric Monteggia equivalent lesion (PMEL) was reviewed. The functional roles of the ulnar and the related mechanism theories in this injury were analyzed. The status of the radiocapitellar joint in this injury was emphasized. According to the previous statements, a new classification model was proposed and proper diagnosis and treatment approaches were suggested.

Conclusions PMEL should be defined as an ulnar fracture at any level combined with a proximal radial fracture. According to the status of the radiocapitellar joint, it could be divided into three groups. The occult ulnar bowing and delayed radial head dislocation should be a serious concern of orthopedists. Surgical need is usually warranted. Maintaining the ulnar length and securing the radiocapitellar joint are highly recommended.

\section{INTRODUCTION}

Monteggia fracture, named after Giovanni Monteggia in the 19th century and well described and classified by Dr Bado decades ago, involves ulnar fracture and concomitant dislocation of the radial head. The term 'lesion' has gradually superseded those such as 'fracture', 'fracture-dislocation', or 'injury' in the literature, stressing the importance of noticing the radiocapitellar joint and reflecting an increased awareness of the complexity regarding its manifestation and mechanism among orthopedists.

Apart from the established four types proposed by Bado, the groups of 'Monteggia equivalent lesion/variant' have been considerably expanded during decades of sporadic case reports. The boundary of that definition has largely been blurred. Also, especially in pediatric patients when immature radiocapitellar epiphysis interferes with judgment and flexible joint allows more frequent subluxation, quite a number of these types tend to be misdiagnosed or neglected owing to the occult presentation of radiocapitellar joint or plastic bowing ulna on radiographs. Yet, throughout these decades, literature has been disproportionally scarce on reviewing this subset of the entity.

The aim of this narrative review was to enumerate the extended cases for this lesion and to achieve a reasonable academic consensus on the definition. Pediatric orthopedists' additional awareness of this variant is expected to develop. We hope that greater understanding and management of the Monteggia equivalent lesion in children are facilitated by this review.

\section{DEFINITION}

The term 'Monteggia equivalent lesion' was first proposed by Jose Luis Bado in his seminal article published in $1967 .{ }^{1}$ In addition to the established four types, he classified a group of lesions that shared a similar mechanism yet presented heterogeneous manifestations with those of 'Monteggia lesion'. Five groups of type I equivalents were described: (Ia) anterior dislocation of the radial head (without obvious ulnar fracture, probably could not be detected due to then examination restriction); this group also includes the 'pulled elbow syndrome' in the child; (Ib) fracture of the ulnar diaphysis with fracture of the neck of the radius; (Ic) fracture of the neck of the radius; (Id) fracture of the ulnar diaphysis with fracture of the proximal third of the radius; and (Ie) fracture of the ulnar diaphysis with anterior dislocation of the radial head and fracture of the olecranon (figure 1). He categorized some kinds 

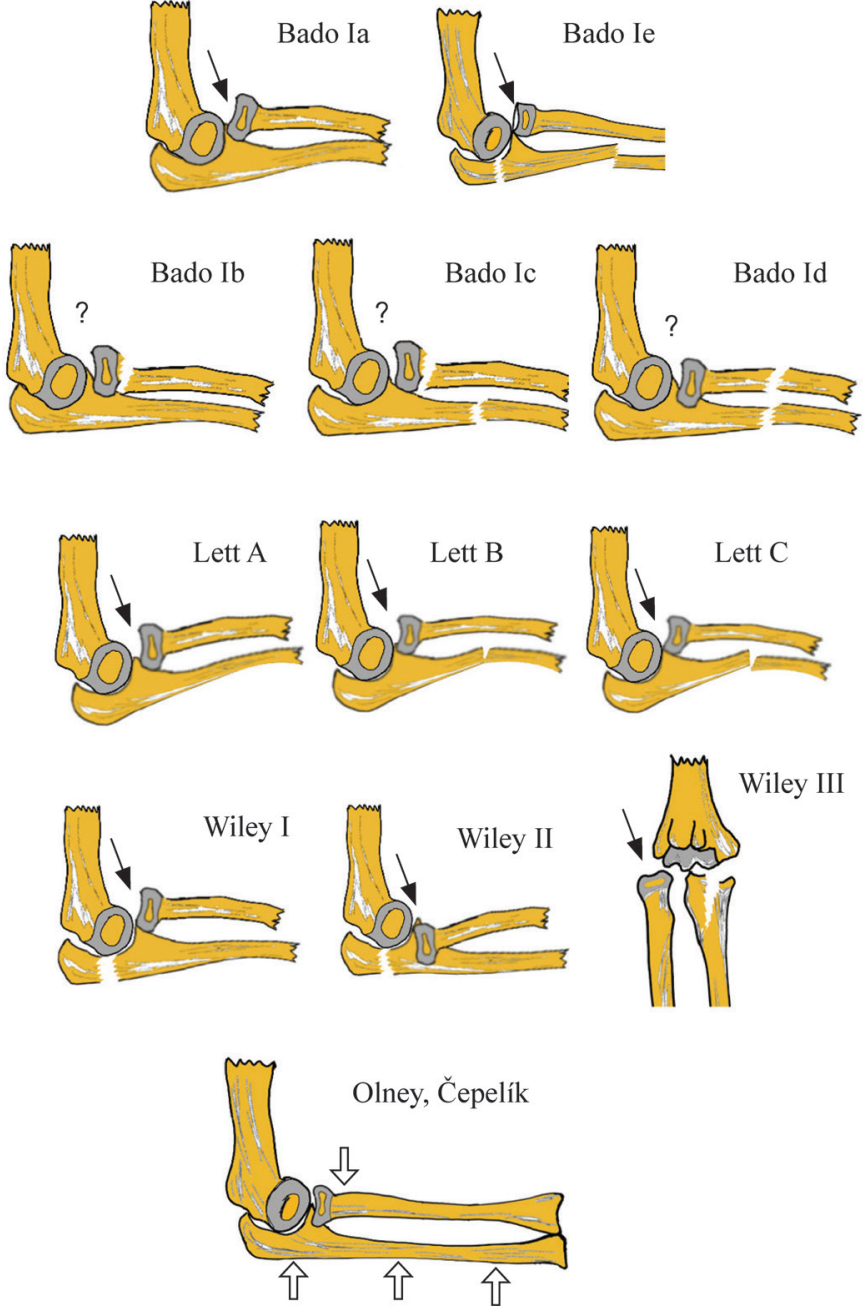

Figure 1 Evolution for the definition of pediatric Monteggia equivalent lesion. Bado's classification: five types were mentioned. Note the anterior dislocation of the radiocapitellar joint in types la and le. Lett's type A-C depicted anterior bowing of ulna. Wiley's I-III described anterior, posterior and lateral dislocation of the radiocapitellar joint, each combined with an olecranon fracture. More universal definition from Olney and Čepelík. Question marks indicate the undescribed status of radiocapitellar joint in subtypes $\mathrm{Ib}-\mathrm{ld}$. Arrows show the associated anterior dislocation of the radiocapitellar joint. Hollow arrows show the proximal radial fracture combined with proximal, middle or distal third fractures of the ulna.

of epiphysial or radial neck fracture into type II equivalent. As shown in figure 1, type Ib-Id and type II equivalents did not specifically involve the status of the radiocapitellar joint, which was contrary to those type I-IV lesions that each combined with a dislocated radial head. Besides, he did not mention any of the type III and IV equivalents (figure 1).

Subsequent studies had been more willing to fill that categorical vacancy. Following the logic of Bado classification for Monteggia equivalent lesion, Ravessoud ${ }^{2}$ put a pediatric case of lateral condylar fracture and ipsilateral ulnar shaft fracture into type III equivalent, while another author categorized an adolescent case of radiocapitellar dislocation and concomitant fracture of the supracondylar humerus and distal radius as type IV equivalent. ${ }^{3}$

The concept of 'equivalent' for the pediatric population continued to evolve as further elucidation came from two study groups separately in the same year, 1985. Letts and his colleagues ${ }^{4}$ stressed the importance of noticing the anterior bend or greenstick of immature ulnar and subsequently dislocated or subluxation of the radiocapitellar joint in pediatric Monteggia lesion. They took these occasions into the expanded equivalent lesions. Wiley and Galey $^{5}$ placed specific concern on the olecranon and proximal ulnar fracture-related radiocapitellar joint issues. They suggested including those three scenarios into type I-III pediatric Monteggia equivalent lesions (PMELs), respectively. That proposition conflicted with the former opinion, which specifically excluded the olecranon-involved type out of the category of Monteggia lesion. $^{6}$

Olney and Menelaus's ${ }^{7} 102$ case studies on PMEL in 1989 offered a periodical review for Monteggia equivalent lesion in children. Out of 102 cases in that study, 17 were deemed as the equivalent. Aside from two cases of radiocapitellar dislocation with bowing ulna and one with concomitant olecranon and ulnar shaft fracture, 14 of them, with concomitant fracture of the ulnar shaft 

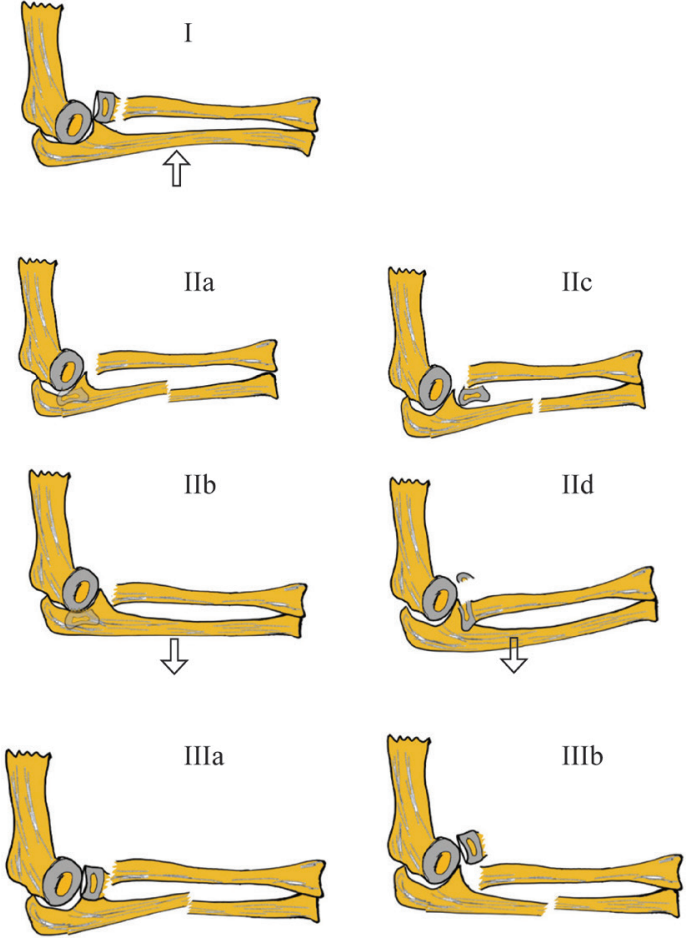

Figure 2 Proposed classification based on Olney and Čepelík. Group I: anterior ulnar plastic deformity combined with radial neck fracture and anterior radiocapitellar joint dislocation. Arrow shows the anterior bowing. Group II: ulnar fracture associated with posterior radial neck fracture and posterior radiocapitellar joint dislocation. Four subtypes were observed in the literature cases. Group III: ulnar shaft fracture associated with a radial neck fracture, the most frequently seen subtype. Arrows indicate posterior bowing.

and radial head/neck, were ranked as the third most common in their series, second only to true Monteggia lesion of Bado types I and III.

The discussion has never stopped over 'the equivalent' as to its presentation, injury combination, mechanism, diagnosis, and management in the past several decades when a few sporadic case reports demonstrated some of the unclassifiable 'equivalent'. ${ }^{8-20}$

A most recent contribution towards the definition has been made by Čepelík $e t a l^{21}$ and his group in their study of 111 cases. They defined it as an ulnar fracture at any level combined with 'displaced' (with undisplaced or minimal displaced ones were not included) proximal radial fracture, which embraced Olney criteria and was consistent with Bado Ia-Ic. Those with the radiocapitellar dislocation or subluxation induced by ulnar bowing or incomplete fracture (Lett I and II) and by olecranon fracture (Wiley I-III) were included into 'true' Bado type I-III counterparts, respectively, and thus were excluded from the equivalent lesion. This is a big advance for the currently highly heterogeneous definition of PMEL. Yet, though this definition, like the Olney one, brought forward the association of proximal radial fracture in PMEL, they both failed to further specify it. As previous case studies have shown, the proximal radial fracture, involving the region of the radial head, neck, and especially the radiocapitellar joint presented extremely complicated attributes, thus justified a more elaborated classification on it for the PMEL (figure 1).

Thus, based on Olney's and Čepelík's definitions, and taking various elaborations of the lesion type in the proximal radius region into account, we could try to sort out a currently reasonable subcategorization strategy for PMEL mostly according to the status of radiocapitellar joint (figure 2).

\section{PRESENTATION}

Historical case reports on PMELs are listed in the four tables as follows. All but two of these specific cases fit Čepelík's definition of 'displaced proximal radial fracture and concomitant ulnar fracture at any level'. The 14 cases were roughly divided into four groups according to the migration direction of the radial head or the main part of the radial head relative to the capitellum. Only two cases ${ }^{89}$ in the literature were sorted into group I and identified as with anterior dislocation of the radiocapitellar joint. Both were late present or neglected cases with occult ulnar fracture (table 1). Four with posterior dislocation of the radial head were sorted into group II, among which two with undiscovered posterior bowing of ulna underwent an unpleasant prolonged treating process and one with radial head fracture (Salter-Harris IV) was the only one in this series (table 2). Intact radiocapitellar joint occurred in six cases, which constituted group III and was also the only described type in Olney's or Čepelík's series (table 3). The other two cases, with either a fracture of humerus or distal third radius, were not combined with a radial neck or head fracture and thus did not affiliate to Čepelík's definition. They were suggested to be classified as true Monteggia fractures in this review (table 4).

\section{Proximal radius and radiocapitellar joint}

The involvement of the proximal radius in the PMEL brought up its entanglement with the definition of the isolated pediatric radial neck and head fracture. The rarely used Chamber ${ }^{22}$ classification for pediatric radial neck fracture (PRNF) ascribed its group II injuries, that is, those with primary displacement of radial neck (and largely intact radial head and radiocapitellar joint), to Monteggia equivalent lesions, the group III in our review (figure 2). And the Chamber group I was compatible with currently prevailing classifications of Judet ${ }^{23}$ and O'Brien, ${ }^{24}$ which were mostly based on Jeffery's ${ }^{25}$ in 1950 , grading the severity according to the lateral angulation and displacement of the radial head (figure 3). This pattern of radial neck fracture might lead to gradual angulation deformity of the radial head and to subsequent incongruity of radiocapitellar joint and played a role in some of the delayed PMEL, like the two cases of group I in the first table (table 1). Additional patterns of PRNFs, described by Jeffery and subsequent 


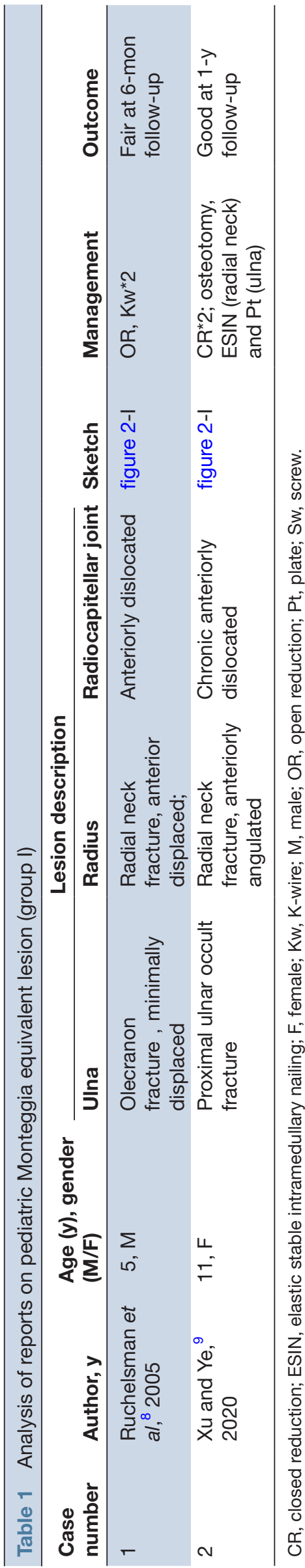

authors, ${ }^{26-29}$ were also found in group II (table 2) of this review, where momentary partial elbow dislocation and relocation caused the displacement of the radial head. Combined with ulnar posteriorly bowing, it generated two late presented PMELs, prolonging the treating process (figure 3 ).

The review suggests only a small fraction of radial fracture types that occur in the PMEL could apply the Judet and O'Brien classifications, whereas on most occasions, orthopedists have to resort to the less prevailing Chamber classification to describe those with radial neck and shaft displaced and radial head and radiocapitellar stayed in situ (table 3). Moreover, the classification system this review provided for PMEL has put more concern on radiocapitellar status and covers most PMEL types as recently reported (figure 2 ).

\section{Ulnar}

Both Olney's and Čepelík's definitions on PMEL have made it clear that it combined with an ulnar fracture at any level (proximal third, middle shaft, or distal third), of any form (displaced fracture, greenstick fracture, or occult bowing). They did not specify the aspects of the angulation or rotation direction of fracture. Though most of the historical cases were not able to verify the rotation direction or degree, they did note anterior or posterior angulation. In the 12 cases, we recorded nine anterior and three posterior angulations of the ulna. Among them, two anterior angulations ${ }^{89}$ and two posterior angulations ${ }^{11} 12$ were verified as occult or obscure fracture, the modalities of which were either anterior or posterior chronic bowing of the ulna, in light of the muscular and ligamental linkage, leading to the chronic dislocation of the radiocapitellar joint.

The precise mechanism for PMEL has not been described. The modern consensus is that the PMELs share the similar mechanism with the true Monteggia lesion. However, even for the true Monteggia lesion, a universal mechanism still does not exist. Well-accepted ones are direct trauma, hyperpronation, and hyperextension. The direct blow theory is the most traditional proposed mechanism for true Monteggia lesions. It was first described by Monteggia ${ }^{30}$ himself and was elaborated well by Speed and Boyd, ${ }^{31}$ and then was endorsed by Smith. ${ }^{32}$ It ascribed the dislocation of the radial head to the 'continued deformation or direct pressure' of the ulnar fracture, which was caused by direct force on the fracture site. Moreover, this force from continued deformation or direct pressure could also be on the pediatric proximal radial epiphysis transversely. The radial neck might break off before rupture of the annular ligament or lateral elbow capsule, in a skeletal immature system where ligament exceeds bony strength, generating group III of this literature series, the most common PMELs. The hyperpronation theory was suggested by Evans, ${ }^{33}$ who postulated the rotational force the proximal radius bears to be generated when the forearm is excessively pronated and the radius cross over mid-ulna. However, 


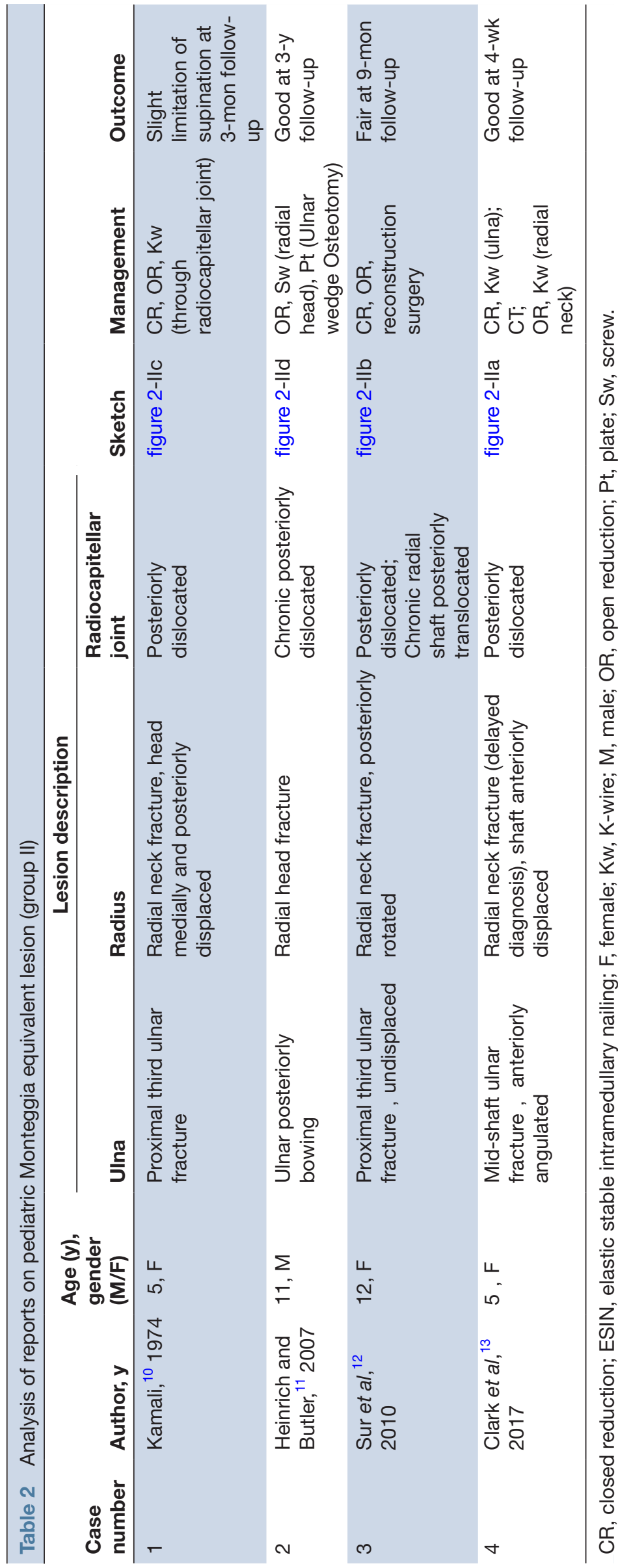

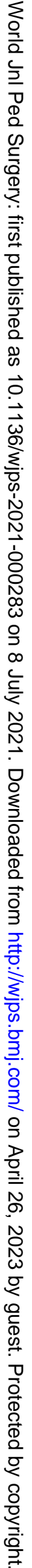




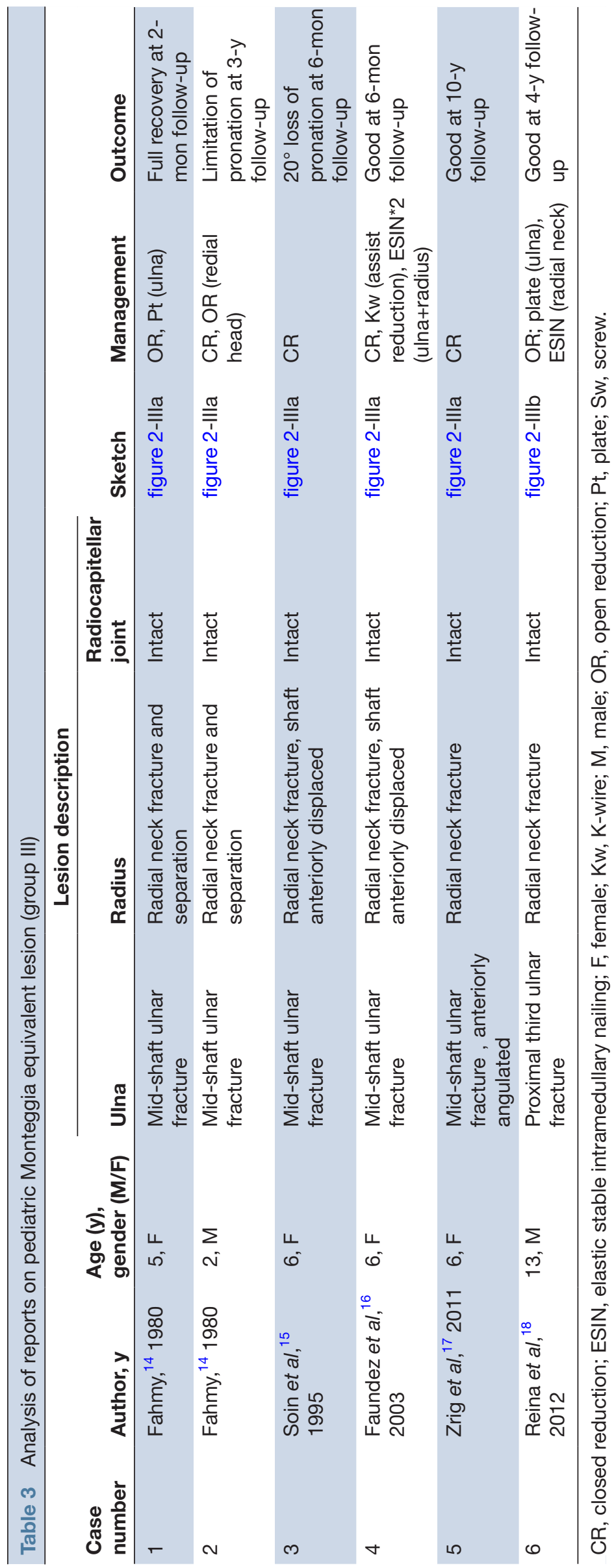

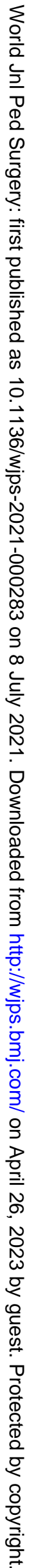


Table 4 Analysis of reports on pediatric Monteggia equivalent lesion (group 4)

\begin{tabular}{|c|c|c|c|c|c|c|c|}
\hline \multirow[b]{2}{*}{$\begin{array}{l}\text { Case } \\
\text { number }\end{array}$} & \multirow[b]{2}{*}{ Author, y } & \multirow[b]{2}{*}{$\begin{array}{l}\text { Age }(y), \\
\text { gender (M/F) }\end{array}$} & \multicolumn{3}{|c|}{ Lesion description } & \multirow[b]{2}{*}{ Management } & \multirow[b]{2}{*}{ Outcome } \\
\hline & & & Ulna & Radius & $\begin{array}{l}\text { Radiocapitellar } \\
\text { joint }\end{array}$ & & \\
\hline 2 & $\begin{array}{l}\text { Kim et al, }{ }^{20} \\
2014\end{array}$ & $6, M$ & $\begin{array}{l}\text { Anterior ulnar } \\
\text { bowing* }\end{array}$ & $\begin{array}{l}\text { Medial humeral } \\
\text { condyle fracture* }\end{array}$ & $\begin{array}{l}\text { Anteriorly } \\
\text { dislocated }\end{array}$ & $\begin{array}{l}\mathrm{CR}, \mathrm{Kw}^{\star} 2 \text { (medial } \\
\text { condyle) }\end{array}$ & $\begin{array}{l}\text { Good at 1-y } \\
\text { follow-up }\end{array}$ \\
\hline
\end{tabular}

${ }^{*}$ Concomitant distal humeral injury.

$\mathrm{CR}$, closed reduction; ESIN, elastic stable intramedullary nailing; F, female; Kw, K-wire; M, male; OR, open reduction.

it was disputed by Tompkins, ${ }^{34}$ who raised the theory of combined dynamic and static force for the nature of the cadaveric study and the fact that the spiral fracture of ulna resulting from the rotational force was rarely seen clinically. In group I and group II PMELs, the classical mechanism for radial neck fracture might be combined with those proposed for Monteggia. However, more highlevel studies are still needed to elucidate the precise mechanism for PMELs.

\section{Other related parts}

Previous studies ${ }^{2}{ }^{20}$ have also recorded Monteggia lesion associated with lateral condyle, supracondylar and medial condyle fracture; the former two were noted

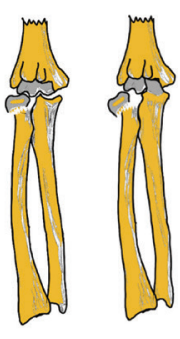

I
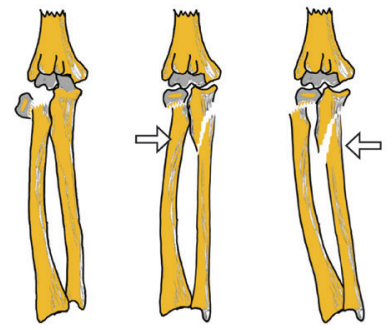

II

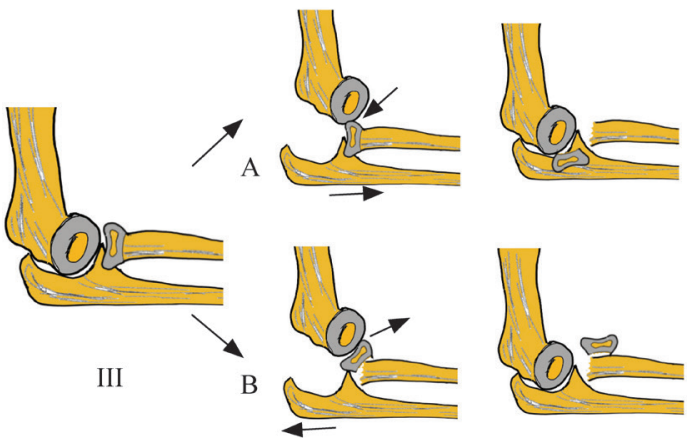

Figure 3 Various categorizations for proximal radial fracture. I: prevailing classification of Jeffery, Judet or O'Brien on lateral displacement and angulation of the radial head. II: chamber group II, where the radial head stayed in situ; primary displacement is in the radial shaft, found in group III of this review. III: another pattern of the radial neck fracture, involved in the posterior elbow dislocation and reduction mechanism, found in group II of this review. Arrows and hollow arrows show the direction of the force. as equivalent Bado type III and type IV. Aside from the lesions of the distal humerus, distal radial and ulnar fracture have also been found to be combined with a radial head dislocation ${ }^{19}$ However, as we put it, we would like to put these combinations to true Monteggia counterparts and stick with the primary definition for PMELs of the presentation of a proximal radial fracture, to elucidate the currently extremely entangled terms.

\section{DIAGNOSIS}

Diagnosis for PMELs has always been tricky for the highly heterogeneous presentation, obscure mechanism, and difficulty of discerning the immature radiocapitellar joint and the occult ulnar fracture patterns. Yet, regarding the high risk of misdiagnosis for PMELs and atrocious prognosis for shortened ulna and deformed forearm, and chronically degenerated radiocapitellar joint when subluxation or dislocation of it is unrecognized and untreated, the orthopedists are urgently recommended to acquire proper diagnosis tips.

Physical examinations may reveal non-specific swelling and tenderness of the forearm and elbow, inability to rotate the forearm, flex, and extend the elbow. Considering children's nature, orthopedists will currently have to rely heavily on imaging measures, traditionally the anteroposterior (AP) and lateral radiographs, to diagnose the PMELs. As the tabled case series shows, the AP and lateral X-rays might not always be accountable initially in discovering a radial neck or head fracture, for the vagary induced by unossified physis ${ }^{810} 13$ or the shading from adjacent bony structure. ${ }^{111316}$ Yet, it is still an effective first-line approach to discern most of the group III cases. For group I and II cases, where the radiocapitellar joint matters, the classical principle of the radiocapitellar line, named by Storen, ${ }^{35}$ intersects the capitellum in all views could help. However, a recent study has found approximately $16 \%$ of the normal elbow does not fit that law, especially in AP view of children under 5 years old. ${ }^{36}$ Thus, the lateral humeral line was introduced by Souder et $a \hat{l}^{37}$ to complement evaluating radiocapitellar dislocation or incongruity. For all of the PMEL cases, the plastic deformity or gradual malunion of the ulna was an easily neglected condition, which could be responsible for delayed dislocation of the radiocapitellar joint. The line drawn tangential to the posterior border of the ulnar 
diaphysis has been introduced by Lincoln and Mubarak ${ }^{38}$ to determine the 'ulnar bow sign', and the maximum perpendicular distance of more than $3 \mathrm{~mm}$ of this line from the ulnar shaft would be deemed as a possible Monteggia equivalent.

Most of the time, plain radiographs would be sufficient for an acute PMEL. However, for an uncertain occasion or a prolonged history, a vast majority of the authors in this literature series applied advanced examinations, such as CT or magnetic resonance, to discover the occult ulnar fracture or unapparent radiocapitellar joint dislocation. Besides, under anesthesia, techniques, such as B-ultrasonic ${ }^{39}$ or arthrography, ${ }^{40}$ could also be employed to ensure that the radiocapitellar joint was congruent for groups I and II of the PMELs. ${ }^{41}$

\section{MANAGEMENT}

Management strategies for the PMELs should depend on the categories. For the most common group III cases, achievement and maintaining the fracture reduction are the priority. In Olney and Menelaus's ${ }^{7}$ series, 10 out of 14 were surgically treated, and the operating focus was to prevent 'common deformity of varus angulation'; and Čepelík $e t a \iota^{21}$ 's experience for their 38 cases of 'displaced Monteggia equivalent' was a total rate of $76 \%$ to internally fix, within which $23.5 \%$ were open reducted. The six literature cases we collected revealed four operation choices. As Čepelík $e t a l^{21}$ explained, the instability provided by long spiral or oblique fracture of the ulna, the intra-articular fracture of the olecranon, and the hindering of the proximal radial fracture reduction by the incarcerated annular ligament might be the indication for surgery. Moreover, the pins or the elastic nailings are the most used fixations to stabilize the fracture. Plate and screws are sometimes used to control the ulnar varus better.

For group II of the PMEL, a relatively scarce case number makes the treatment choice hard to decide. However, the involved proximal radial fracture might apply the existing management protocol for posterior located Judet IVb or O'Brien III types. Closed reduction seems extremely difficult for this type and has a chance to reverse the radial head $180^{\circ}$, turning artificial surface against the fracture side. ${ }^{12}{ }^{42}$ The alternative way is to use the percutaneous leverage technique to assist reduction. ${ }^{43}$ Rigid Kirschner wire or Metaizeau elastic nailing were the most frequently suggested of this technique. Open reduction for proximal radial fracture and ulnar fracture could be served as in group I, though concern over the issue of potential ulnar fracture still exists. Two literature reports ${ }^{11} 12$ resented this type with a posterior bowing of ulnar, which went through delayed radiocapitellar joint dislocation and underwent unscheduled operations.

Group I in our review was extremely rare. The two cases demonstrated similar presentations. Considering the late presenting nature and prolonged treatment process of both cases, the diagnosis outweighed the management.
Initial anterior bowing of the ulna and subsequent potential for dislocation of the radial head are anticipated to be discovered as soon as possible.

\section{CONCLUSION}

PMEL makes up a considerable proportion of all pediatric Monteggia lesions. It is not properly recognized among the academic community and is frequently misdiagnosed and maltreated. The definition should be unified as an ulnar fracture at any level combined with a proximal radial fracture. We propose to divide it into three groups according to the status of the radiocapitellar joint. The occult ulnar plastic deformity and delayed radial head dislocation should be serious concerns of orthopedists. Surgical need is usually warranted. Maintaining the ulnar length and securing the radiocapitellar joint are highly recommended.

Contributors All of the authors have read and approved the manuscript. Specific authors' contributions are as follows: LX contributed to conceptualization, data curation, formal analysis, funding acquisition, Investigation, methodology, supervision, validation, visualization, writing - original draft and writing - review \& editing; WY contributed to conceptualization and supervision; HL cotributed to data curation, formal analysis and funding acquisition; JX contirbuted to validation and visualization; WZ contributed to data curation Investigation; ZZ contributed to data curation and formal analysis; YY contributed to data curation and methodology.

Funding The authors have not declared a specific grant for this research from any funding agency in the public, commercial or not-for-profit sectors.

Competing interests None declared.

Patient consent for publication Not required.

Ethics approval Not required.

Provenance and peer review Not commissioned; externally peer reviewed.

Data availability statement Data are available in a public, open access repository. As a review article, the data is acquired from the previously published works.

Open access This is an open access article distributed in accordance with the Creative Commons Attribution Non Commercial (CC BY-NC 4.0) license, which permits others to distribute, remix, adapt, build upon this work non-commercially, and license their derivative works on different terms, provided the original work is properly cited, appropriate credit is given, any changes made indicated, and the use is non-commercial. See: http://creativecommons.org/licenses/by-nc/4.0/.

ORCID iD

Lujie Xu http://orcid.org/0000-0003-2822-6549

\section{REFERENCES}

1 Bado JL. The Monteggia lesion. Clin Orthop Relat Res 1967;50:71???86-86.

2 Ravessoud FA. Lateral condylar fracture and ipsilateral ulnar shaft fracture: Monteggia equivalent lesions? J Pediatr Orthop 1985;5:364-6.

3 Arazi M, Oğün TC, Kapicioğlu MI. The Monteggia lesion and ipsilateral supracondylar humerus and distal radius fractures. $J$ Orthop Trauma 1999;13:60-3.

4 Letts M, Locht R, Wiens J. Monteggia fracture-dislocations in children. J Bone Joint Surg Br 1985;67:724-7.

5 Wiley JJ, Galey JP. Monteggia injuries in children. J Bone Joint Surg Br 1985;67:728-31.

6 Bruce HE, Harvey JP, Wilson JC. Monteggia fractures. J Bone Joint Surg Am 1974;56:1563-76.

7 Olney BW, Menelaus MB. Monteggia and equivalent lesions in childhood. J Pediatr Orthop 1989;9:219-23.

8 Ruchelsman DE, Klugman JA, Madan SS, et al. Anterior dislocation of the radial head with fractures of the olecranon and radial neck in 
a young child: a Monteggia equivalent fracture-dislocation variant. $J$ Orthop Trauma 2005;19:425-8.

9 Xu L, Ye W. Radial neck fracture or Monteggia equivalent lesion: delayed radial head subluxation in an adolescent and review of literature. BMC Musculoskelet Disord 2020;21:282.

10 Kamali M. Monteggia fracture. presentation of an unusual case. $J$ Bone Joint Surg Am 1974;56:841-3.

11 Heinrich SD, Butler RA. Late radial head dislocation with radial head fracture and ulnar plastic deformation. Clin Orthop Relat Res 2007;460:258-62.

12 Sur YJ, Park J-B, Song SW. Pediatric posterior monteggia lesion: a greenstick fracture of the proximal ulnar metaphysis with radial neck fracture. A case report. J Orthop Trauma 2010;24:e12-16.

13 Clark TR, Merriott DS, Gonzales JA. Complex Monteggia fracture in a 5 year old. J Pediatr Orthop B 2017;26:36-40.

14 Fahmy NR. Unusual Monteggia lesions in children. Injury 1981;12:399-404.

15 Soin B, Hunt N, Hollingdale J. An unusual forearm fracture in a child suggesting a mechanism for the Monteggia injury. Injury 1995;26:407-8.

16 Faundez AA, Ceroni D, Kaelin A. An unusual Monteggia type-I equivalent fracture in a child. J Bone Joint Surg Br 2003;85:584-6.

17 Zrig M, Mnif H, Koubaa M, et al. An unusual Monteggia type I equivalent fracture: a case report. Arch Orthop Trauma Surg 2011;131:973-5.

18 Reina N, Laffosse J-M, Abbo O, et al. Monteggia equivalent fracture associated with Salter I fracture of the radial head. J Pediatr Orthop B 2012;21:532-5.

19 Peter VK. Rare presentation of a type I Monteggia fracture. Emerg Med J 2002;19:88-9.

$20 \mathrm{Kim}$ YS, Lee HM, Kim JP, et al. Unusual presentation of a type 1 Monteggia equivalent lesion: simultaneous medial humeral condyle fracture with ipsilateral anterior dislocation of the radial head and acute plastic bowing of the ulna. J Pediatr Orthop B 2014;23:383-8.

21 Čepelík M, Pešl T, Hendrych J, et al. Monteggia lesion and its equivalents in children. J Child Orthop 2019;13:560-8.

22 Chambers HG. Fracture of the proximal radius and ulna. In: Beaty JH, Kasser JR, eds. Rockwood and Wilkins fractures in children. 5 edn. PA: Lippincott Williams and Wilkins, Philadelphia, 2001: 485-528.

23 Basmajian HG, Choi PD, Huh K, et al. Radial neck fractures in children. J Pediatr Orthop B 2014;23:369-74.

24 O'Brien PI. Injuries involving the proximal radial epiphysis. Clin Orthop Relat Res 1965;41:51-8.

25 Jeffery CC. Fractures of the head of the radius in children. $J$ Bone Joint Surg Br 1950;32-B:314-24.
26 Newman JH. Displaced radial neck fractures in children. Injury 1977;9:114-21.

27 Ward WT, Williams JJ. Radial neck fracture complicating closed reduction of a posterior elbow dislocation in a child: case report. $J$ Trauma 1991;31:1686-8.

28 Carl AL, Ain MC. Complex fracture of the radial neck in a child: an unusual case. J Orthop Trauma 1994;8:255-7.

29 Fraser KE. Displaced fracture of the proximal end of the radius in a child. A case report of the deceptive appearance of a fragment that had rotated one hundred and eighty degrees. J Bone Joint Surg Am 1995;77:782-3.

30 Monteggia GB. Instituzioni Chirurgiche. Milan: Maspero, 1814.

31 Speed JS, Boyd HB. Treatment of fractures of ulna with dislocation of head of radius: Monteggia fracture. JAMA 1940;125:1699.

32 Smith FM. Monteggia fractures; an analysis of 25 consecutive fresh injuries. Surg Gynecol Obstet 1947;85:630-40.

33 Evans EM. PRONATION injuries of the forearm. $J$ Bone Joint Surg Br 1949;31-B:578-88.

34 Tompkins DG. The anterior Monteggia fracture: observations on etiology and treatment. J Bone Joint Surg Am 1971;53:1109-14.

35 Storen G. Traumatic dislocation of the radial head as an isolated lesion in children; report of one case with special regard to roentgen diagnosis. Acta Chir Scand 1959;116:144-7.

36 Ramirez RN, Ryan DD, Williams J, et al. A line drawn along the radial shaft misses the capitellum in $16 \%$ of radiographs of normal elbows. J Pediatr Orthop 2014;34:763-7.

37 Souder CD, Roocroft JH, Edmonds EW. Significance of the lateral humeral line for evaluating Radiocapitellar alignment in children. $J$ Pediatr Orthop 2017;37:e150-5.

38 Lincoln TL, Mubarak SJ. "Isolated" traumatic radial-head dislocation. J Pediatr Orthop 1994;14:454-7.

39 Davidson RS, Markowitz RI, Dormans J, et al. Ultrasonographic evaluation of the elbow in infants and young children after suspected trauma. J Bone Joint Surg Am 1994;76:1804-13.

40 Lee D-H, Han S-B, Park J-H, et al. Elbow arthrography in children with an ulnar fracture and occult subluxation of the radial head. $J$ Pediatr Orthop B 2011;20:257-63.

41 Nicholson LT, Skaggs DL. Proximal radius fractures in children. $J$ Am Acad Orthop Surg 2019;27:e876-86.

42 Sirois ZJ, Kreul SM, Shank CF. Inadvertent radial head inversion during closed reduction of a pediatric radial neck fracture. J Am Acad Orthop Surg 2019;27:e414-7.

43 Cha SM, Shin HD, Kim KC, et al. Percutaneous reduction and leverage fixation using K-wires in paediatric angulated radial neck fractures. Int Orthop 2012;36:803-9. 